\section{CPS-272 ANALYSIS OF ADVERSE REACTION REPORTS BEFORE AND AFTER THE USE OF EQUIVALENT IMATINIB IN A TERTIARY HOSPITAL}

${ }^{1}$ E Specogna*, ${ }^{2} \mathrm{MT}$ Chiarelli, ${ }^{2} \mathrm{C}$ Naddeo, ${ }^{1} \mathrm{M}$ Bettio, ${ }^{2} \mathrm{M}$ Mazzucchelli, ${ }^{2} \mathrm{~F}$ Venturini. ${ }^{1}$ Scuola di Specializzazione in Farmacia Ospedaliera - Universita' Degli Studi di Milano, Dipartimento di Scienze Farmaceutiche, Milano, Italy; ${ }^{2}$ Fondazione Irccs ca' Granda Ospedale Maggiore Policlinico, U.O.C. Farmacia, Milano, Italy

\subsection{6/ejhpharm-2019-eahpconf.421}

Background Several patients treated with Glivec for chronic myeloid leukaemia were switched to the equivalent drug imatinib, after the expiry of the patent. However, the switch in some patients has revealed a suspected adverse reaction, which led to the re-use of the originator drug.

Purpose The aim of the study was to analyse the incidence and type of reports of adverse reactions before and after the switch by comparing them with national data.

Material and methods At our hospital, the use of equivalent imatinib began massively in October 2017. For the analysis of 7 months, two periods were compared: October 2016 to May 2017 (period 1: pre-switch) and October 2017 to May 2018 (period 2: post-switch). The source of the reports is the pharmacovigilance's database of the Italian drug agency. The formulations in the market were also analysed in terms of composition.

Results In period 1, 77 patients were treated with Glivec and one adverse drug reaction was reported (1.3\% eczema). During period 2, 69 patients were treated and there were five reports (two epigastric pain, diarrhoea, pruritus, one vomiting, one stomatitis, oedema, dyspnea, one skin rash), all with the equivalent drug (7.2\%). None of these were serious. Because of the intolerance, three patients were switched back to Glivec. The increase in the number of reports was also reflected in the national data. From the authorisation of the marketing to the expiration of the patent (192 months) 330 reports of adverse reactions to Glivec were sent (1.7 ADR/month), while from the patent expiry to May 2018, 174 adverse reactions were reported and at least 123 were from an imatinib equivalent (10 ADR/month). The increase in reports post-switch was $83 \%$. Regarding the formulation, there are differences in terms of pharmaceutical form (capsules/tablets), excipients and type of coating.

Conclusion Results suggest a possible correlation between the switch and the increase in the number of reports. However, as pointed out by AIFA, whenever a new equivalent drug comes on the market, the attention to reports may increase. It would be interesting to understand which components have caused adverse reactions and to identify patients at risk.

\section{REFERENCES AND/OR ACKNOWLEDGEMENTS}

No conflict of interest.

\section{CPS-273 PHARMACY INTERVENTION AND DRUG PRESCRIPTION REGULATIONS IN A TERTIARY HOSPITAL}

P Stathopoulou*, V Papandreou, V Papadopoulou, G Chatzidimitriou, A Sakka, M Vlachou. General Hospital 'Evaggelismos', Pharmacy Department, Athens, Greece

10.1136/ejhpharm-2019-eahpconf.422

Background Increased rate of inappropriate drug use in combination with limited funding made imperative the implementation of restrictions in order to regulate highly-prescribed drugs consumption, such as ferric carboxymaltose (FC) and human albumin (HA). Additionally, limited availability of HA imposed its use exclusively to evidence-based indications.

To this end, mandatory completion of a designed order form (DOF) for the above-mentioned medicines was introduced as a prerequisite in hospital daily practice.

Purpose To clarify the efficacy of pharmacy intervention (PI) in decreasing irrational drug use and produce a better drug management system.

Material and methods An observational study in a tertiary hospital (945 beds) was conducted in two phases. Data, in the first phase (January 2013-May 2018) were analysed retrospectively, while in the second phase (from June 2018) were studied after PI.

Concerning FC, PI refers to DOF completion where ferritin serum value and previous oral administration of ferric formulations were considered.

As for HA, strict adjustment to clinical guidelines and evidence-based indications were applied throughout the local protocol, along with 2 day treatment per prescription.

Total and per clinic FC and HA monthly average consumption data in the pre- and post-guideline implementation phase was conducted. Moreover, average drug cost was calculated.

Results An augmentative trend throughout the first study period was observed in the overall FC average monthly consumption. Significant variations in FC prescription profiles in clinics of similar specialty were detected. DOF implementation resulted in an overall downsizing of FC utilisation (57\%) and prescribers' modification mentality.

Up to December 2017 HA use presented slight differences (25 kg/per month), whereas limited HA supply during the first semester of 2018 led to an expected consumption decline (15 kg/per month). However, the evidence-based HA administration in combination with the DOF adoption revealed further reduction ( $7 \mathrm{~kg} /$ per month) and effective stock management.

DOF implementation for $\mathrm{FC}$ and $\mathrm{HA}$ resulted in a cost reduction of $€ 16,000 /$ month and $€ 40,000 /$ month, respectively, which corresponds to $€ 672,000 /$ year.

Conclusion The evaluation of PI showed its necessity in order to guarantee the rationalised use of high-cost medications associated with anticipated prescription accuracy and compliance. Due to encouraging results, PI measures in other drugs have been implemented (human immunoglobulin and antibiotics).

\section{REFERENCES AND/OR ACKNOWLEDGEMENTS}

https://doi.org/10.1093/bja/aep393

https://doi.org/10.1186/1471-2326-11-4

No conflict of interest.

\section{CPS-274 ABSTRACT WITHDRAWN}

